OPEN ACCESS

Edited by:

Sunjoo Kang

Cheju Halla University, South Korea

Reviewed by:

Timothy Charles Skinner,

University of Copenhagen, Denmark

Sankalp Das,

Baptist Health South Florida

United States

*Correspondence:

Fikadu Balcha Hailu

fikadubalcha@gmail.com;

f.b.hailu@studmed.uio.no

Specialty section

This article was submitted to

Public Health Education and

Promotion,

a section of the journa

Frontiers in Public Health

Received: 06 August 2018 Accepted: 02 October 2018

Published: 23 October 2018

Citation:

Hailu FB, Hjortdahl $P$ and Moen $A$ (2018) Nurse-Led Diabetes Self-Management Education Improves

Clinical Parameters in Ethiopia.

Front. Public Health 6:302.

doi: 10.3389/fpubh.2018.00302

\section{Nurse-Led Diabetes Self-Management Education Improves Clinical Parameters in Ethiopia}

\author{
Fikadu Balcha Hailu ${ }^{1,2 *}$, Per Hjortdahl ${ }^{1}$ and Anne Moen ${ }^{1}$ \\ ${ }^{1}$ Faculty of Medicine, Institute for Health and Society, University of Oslo, Oslo, Norway, ${ }^{2}$ School of Nursing and Midwifery, \\ Jimma University, Jimma, Ethiopia
}

Background: Unlike in developed countries, the clinical effectiveness of diabetes self-management education (DSME) is not well-studied in the African context. Thus, this study sought to determine effects of DSME on clinical outcomes among type 2 diabetic (T2DM) patients in Ethiopia.

Methods: Before-and-after controlled study design was employed, with random assignment of 116 T2DM adult patients to a nurse-led DSME group and 104 to a treatment-as-usual (comparison) group. A nurse-led DSME with six sessions supported with illustrative pictures handbooks and fliers was customized to local conditions and delivered by trained nurses over 9 months. Our primary outcome was a change in the proportion of people with target glycated hemoglobin ( $\mathrm{HbA} 1 \mathrm{c} \leq 7 \%)$. We used chi-square test and mixed model analysis.

Results: Seventy-eight (67\%) and 64 (62\%) participants assigned to intervention and comparison, respectively completed the study, and included in the final analysis. Mean $\mathrm{HbA} 1 \mathrm{c}$ was significantly reduced by $2.88 \%$ within the intervention group and by $2.57 \%$ within the comparison group. However, change in the proportion of participants with target $\mathrm{HbA} 1 \mathrm{c}$ and end-line mean $\mathrm{HbA} 1 \mathrm{c}$ difference between the groups were not significant. Adjusted end-line fasting blood sugar (FBS), systolic blood pressure (SBP), and diastolic blood pressure (DBP) were significantly lower in the intervention group, by $27 \pm 9 \mathrm{mg} / \mathrm{dL}, 12 \pm 3$, and $8 \pm 2 \mathrm{mmHg}$, respectively.

Conclusion: After 9 months of nurse-led DSME, HbA1c was significantly reduced within both groups but there was no significant difference in $\mathrm{HbA} 1 \mathrm{c}$ between groups. The intervention also showed some clinically significant effects on blood pressure and FBS.

Clinical Trial Registration: ClinicalTrials.gov Identifier: NCT03185689, retrospectively registered on June 14, 2017 on ClinicalTrials.gov. https://clinicaltrials.gov/ct2/show/ NCT03185689.

Keywords: DSME, nurse-led, clinical outcomes, long-term glycemic control, type 2 diabetes 


\section{INTRODUCTION}

Diabetes is increasing alarmingly in Africa and developing countries like Ethiopia, probably catalyzed by socioeconomic, demographic, nutritional transitions and childhood malnutrition (1-4). Ethiopia, the leading country in Africa, with over 2.6 million adults living with diabetes $(5,6)$. To postpone diabetesrelated complications and premature deaths, empowering diabetic patients by introducing cost-effective DSME to diabetic care has been recommended (7-9).

DSME has been defined as the "ongoing process of facilitating the knowledge, skill, and ability necessary for prediabetes and diabetes self-care" (10). DSME focuses on making specific behavioral changes and enabling patients to develop effective problem-solving skills and self-efficacy (8). The ultimate goal of DSME is improving clinical outcomes, health status, and quality of life (10-12). Though, since there is no single, best approach of DSME, standards of DSME have been suggested (10).

Studies in developed countries reveal that DMSE is effective in glycemic control, blood pressure control, and weight management (13-19). However, the very limited research in Africa has resulted in conflicting evidence regarding the effectiveness of DSME on long-term glycemic control and other clinical outcomes. An intensive and structured DSME education given by nurses and physicians for 6 months showed significant reduction in $\mathrm{HbA} 1 \mathrm{c}$ among those who received an intervention (20). However, group-based DSME led by ley health promoters in underserved urban South Africa did not show significant mean difference in HbA1c between groups. This study, however, showed significant mean systolic and diastolic blood pressures difference between the intervention and the control groups (21).

Effectiveness and adherence to of DSME may be affected by sociodemographic factors like education, gender, age, employment, onset of diabetes, and food insecurity (22-27). Diabetes education provided by combining group-based and one-to-one delivery strategy was reported to be more effective than either group-based or one-to-one (7). Diabetes education provided over longer time are also effective $(7,19,28)$. Moreover, teach back strategies and use pictures recommended to better accommodate low literate diabetes patients add merit and value to these groups (29).

The effectiveness of DSME delivered by highly trained providers, measured by glycemic control and other clinical parameters, has been established in developed countries (21). Even though Africa has more diabetes-related premature deaths than any other continent, DSME for low-health-literate diabetic African populations in accordance with the local cultural, social,

Abbreviations: ADA, American Diabetes Association; BMI, body mass index; DSME, diabetes self-management education; FBS, fasting blood sugar; HbAlc, glycated hemoglobin; HFIAS, household food insecurity access scale; IDF, International Diabetes Federation; JUMC, Jimma University Medical Centre; LTFU, lost to follow-up; $\mathrm{mg} / \mathrm{dL}$, milligram per deciliter; $\mathrm{mmHg}$, millimeter mercury; NORHED, The Norwegian Programme for Capacity Development in Higher Education and Research for Development; OHAs, oral hypoglycemic agents; RBS, random blood sugar; REK, Norwegian Regional Committee for Medical and Health Research Ethics; SACCADE, Strategic and Collaborative Capacity Development in Ethiopia and Africa; T2DM, type 2 diabetes mellitus; UKDPS, United Kingdom Diabetes Prospective Study; USD, United States Dollar. and economic context has not been well-studied. The challenges expected in developing countries like Ethiopia relates to a) people are less literate and b) health-care providers have limited understanding of the concept and application of health literacy (30). In Africa, nurse-led DSME adapted to the local culture and patients' literacy level could play an important role in reducing diabetes-related complications and premature deaths (31). Although Ethiopia has the largest number of adults with diabetes of any African country, to the best of our knowledge, DSME interventions have yet to be tested or implemented in the Ethiopian context.

The limited findings regarding the effectiveness of DSME on clinical parameters in Africa and Ethiopia indicate a need for controlled studies contextualized to the local situations that can accommodate low-literate diabetic patients. We conducted the present study to test nurse-led DSME model empirically and adjusted the model to accommodate care of low-literate T2DM patients in Ethiopia. Taking glycemic control gaged by HbA1c as a primary outcome, we aimed to increase the proportion of T2DM patients in the intervention group with controlled blood glucose by absolute $15 \%$. Our secondary outcomes included mean differences in $\mathrm{HbA1c}$, fasting blood sugar (FBS), SBP, DBP, body mass index (BMI), and waist circumference between the intervention and comparison groups.

\section{METHODS AND SUBJECTS}

\section{Study Design and Setting}

A controlled before-and-after study was undertaken in Jimma University Medical Centre (JUMC), Ethiopia.

\section{Study Period}

The baseline survey was conducted from February 2016 to May 2016, the DSME intervention was conducted from November 2016 to July 2017, and the end-line survey was conducted from August 2017 to October 2017.

\section{Sampling}

The sample size was calculated using Epi info_7.exe with the assumptions of increasing the proportion of people with target HbA1c $(\leq 7 \%)$ in the intervention group by absolute $15 \%$ with a power of $80 \%$, and one-sided test at 0.05 significance level. Because HbA1c had never been done routinely in the hospital, we used FBS as a reference measure of glycemic control. Moreover, as compared to FBS test, HbA1c less is less likely to be affected by acute blood sugar fluctuations and recommended to indicate glycemic control relatively over a longer time. A cross-sectional study in the same hospital showed that $18 \%$ of diabetes patients had controlled FBS (32). With the addition of $15 \%$ contingency, from the total 447 adult T2DM patients on active follow-up we sought to recruit a total of 240 participants, and 220 agreed to participate in the study.

\section{Participant Recruitment and Treatment Assignment}

Participants were recruited considering their residence, Jimma city and rural districts surrounding Jimma city in Southwest 
Ethiopia. Out of the total 220 participants included at baseline and given individual code number, we randomly assigned 116 to the DSME intervention and 104 to the comparison group, using the Excel random number generator. At the end-line, 78 from the intervention and 64 from the comparison participants were still in the study and included in the final analysis (Figure 1).

\section{Inclusion and Exclusion Criteria}

We identified participants by the age at T2DM diagnoses (above 30 years), body weight (overweight or obese), or type of treatment (taking oral hypoglycemic agents [OHAs], record of intake of OHAs, or insulin and OHAs). Patients with type 1 diabetes or gestational diabetes, pregnant women, people with severe cognitive or physical impairment, and terminally ill people were excluded.

\section{Intervention}

Participants assigned to the DSME treatment were grouped into 8-12 people per session. They participated in six DSME sessions for $\sim 1.5 \mathrm{~h}$ every month for 6 consecutive months. For convenience, all the sessions were held on the date of the participants' routine follow-up, before they were seen by their doctors.

The DSME intervention was offered by $\mathrm{PhD}$ nurse student $(\mathrm{FBH})$ and one clinical nurse fluent in the local languages Afan Oromo and Amharic, and they had been trained for a total of $16 \mathrm{~h}$. The key role of the nurses was facilitating sessions.
The training was supported by handbooks and fliers with colorful, illustrative pictures customized to the local context and patients' literacy level (see Figure 2). Moreover, each of the $1.5 \mathrm{~h}$ DSME session had a series of interlinked activities including nurse facilitated brief education, discussion, experience sharing, take-home activities, conclusion and revision. During each DSME session, nurses facilitate brief education on the specific session topic, lead discussion, facilitate experience sharing among participants on the specific session topic, conclude session, give take-home activities from the specific session and on the next session start session of the day with revising how the participants were undertaking take-home activities (Figure 3).

We used the International Diabetes Federation training manual for Sub-Saharan Africa and other literature as point of departure to customize the DSME (12, 33-39). The content of the booklet was based on the seven key behaviors of DSME recommended by the American Associations of Diabetes Educators (40). For context-appropriate expertise, 27 T2DM patients (not included in the study) and other relevant stakeholders were consulted. The patient handbook was translated into two local languages: Afan Oromo and Amharic, and reviewed by bilingual experts from Jimma University, Ethiopia. The handbooks were distributed to participants during the first session, and fliers were distributed during each session.

The comparison group continued with usual follow-up care. After the end-line survey, the instructional handbook and fliers were also given to the comparison group. A random blood glucose (RBS) or FBS test was done for both groups during the

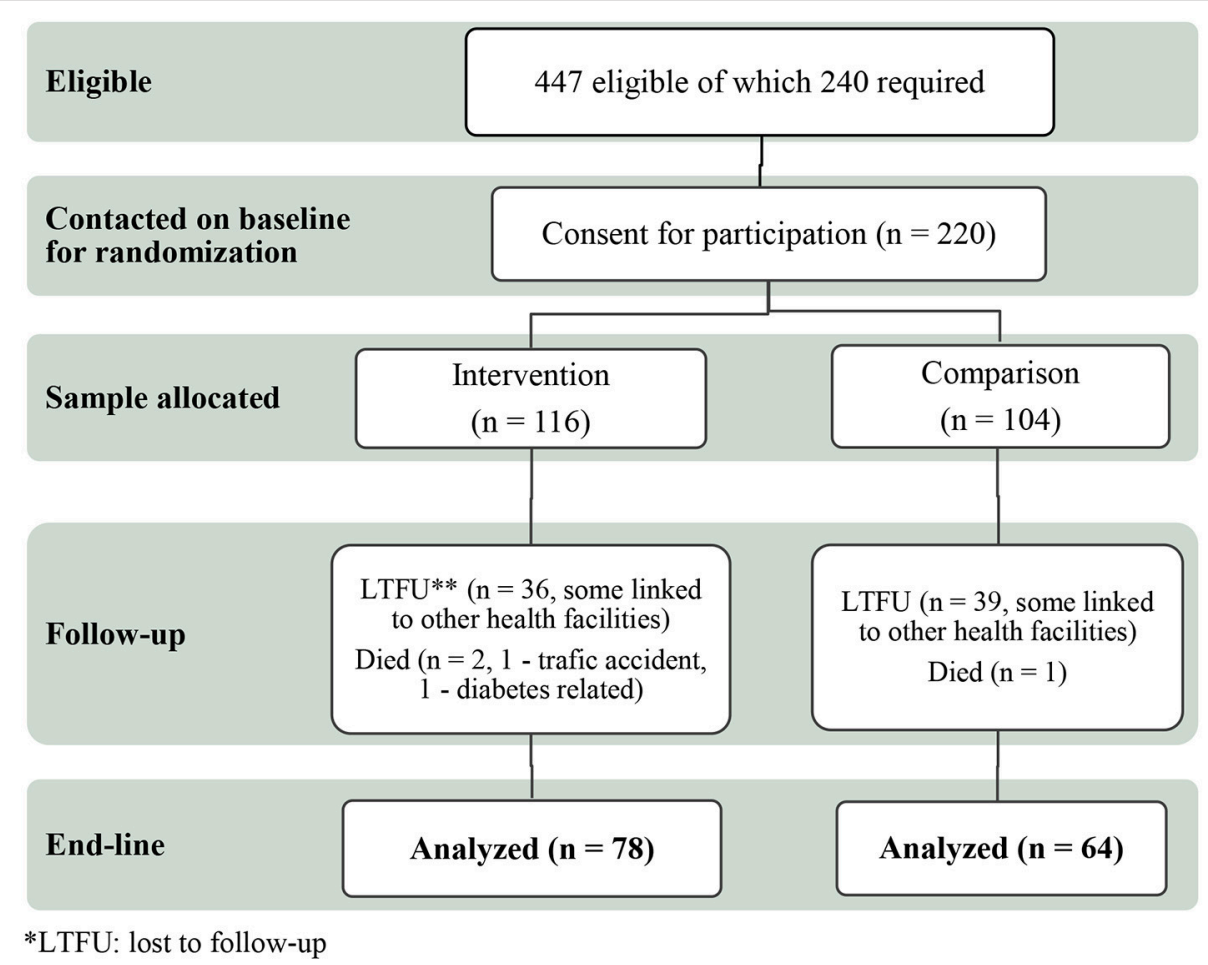

FIGURE 1 | DSME consort flow chart. 
Nyaata Sirri FilachuU (ADA; DiabetesUK, 2015; IDF, 2006)
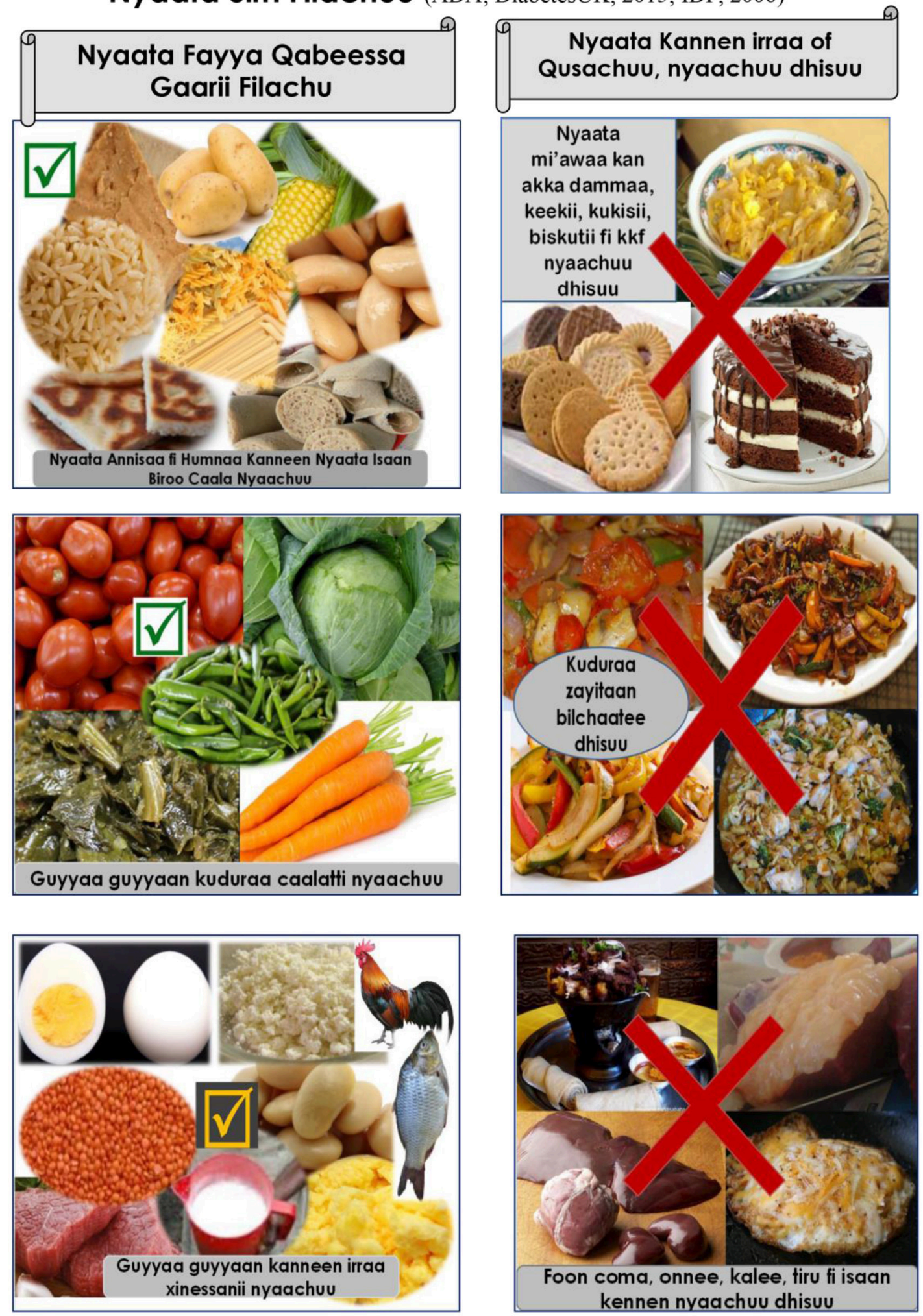

FIGURE 2 | Excerpt from the Afan Oromo language instructional handbook: selecting a healthy diet. 


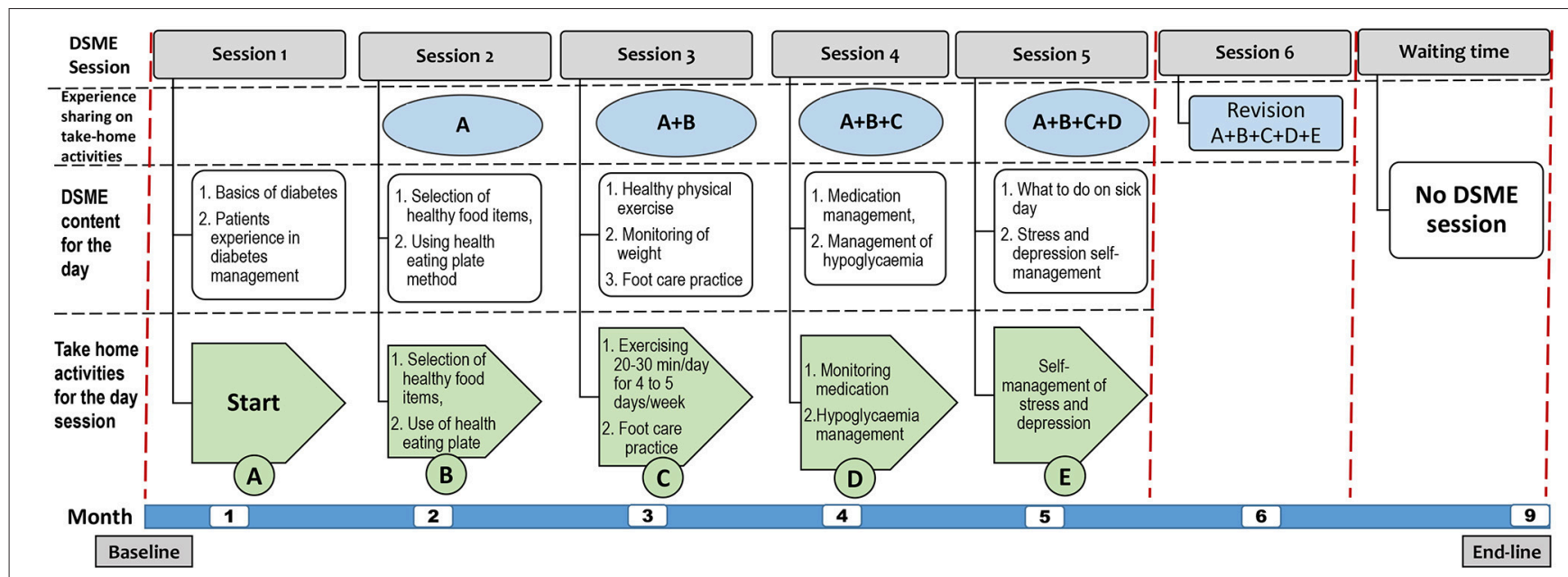

FIGURE 3 | DSME sessions, daily topics, take-home activities, and experience-sharing areas.

follow-up period. To determine the effect of DSME sessions on glycemic control as gaged by $\mathrm{HbAlc}$ level, we measured $\mathrm{HbAlc} 3$ months after the last DSME session.

To reduce loss to follow-up (LTFU), participants were reminded of upcoming sessions by phone, and on every visit, FBS test was provided free of charge for both groups. To reduce risk of information spillover, with the consent of patients we tried to vary the appointment dates of the groups, where the intervention group and the comparison groups would visit the hospital on different days.

\section{Data Collection Tool and Technique}

Data was collected by the trained nurses, using structured interviews, anthropometric measurements, and laboratory tests. One clinical laboratory technician performed lab tests. None of the data collectors were told about which group the participants were assigned to.

Height and weight were measured using a SECA stadiometer. Waist and hip circumference were measured using an inelastic tape measurement. Blood pressure was measured using an ACCOSON aneroid sphygmomanometer. For FBS measurement, a CareSens N I-sens glucometer was used, and for HbAlc, an ABX Pentra 400 HORIBA chemistry machine was used.

For household food insecurity, the household food insecurity access scale (HFIAS), validated in Ethiopia, was utilized (41). The questionnaire had nine occurrence questions, each of which was followed by a frequency-of-occurrence question (42).

\section{Data Analysis}

Data was fed in to EpiData entry client/manager (v. 4.2.0.0) and transported to StataSE 15 for analysis. Frequency distribution was run for proportion of participants with target HbAlc and FBS. A linear mixed model regression analysis was used to determine end-line mean differences in continuous outcome variables between groups. In the model, each of the outcome variables was adjusted for sociodemographic characteristics and patientrelated clinical factors, including baseline targets of respective outcome variables. For the within group changes of the respective continuous outcome variables we used an independent sample $t$-test analysis.

Values of HbA1c $\leq 7 \%$, FBS $<126 \mathrm{mg} / \mathrm{dL}, \mathrm{SBP}<140 \mathrm{mmHg}$, DBP $<90 \mathrm{mmHg}$, and waist circumference $\leq 94 \mathrm{~cm}$ for men and $\leq 80 \mathrm{~cm}$ for women were used as cut-offs (43-45). Households were considered food insecure if the response to occurrence question number 1 was "yes" and the response to the first (1a) frequency-of-occurrence question was "sometimes" or "often," or if response to one of the occurrence questions 2-9 was "yes" (46).

For missing values of outcome variables, we used multiple imputation with the assumption of missing completely at random using twenty imputed data sets both at baseline and endline. Intention-to-treat analysis was used to include participants who had at least an instructional handbook before the end of the intervention period and were assessed for the endline. Accordingly, regardless of number of DSME sessions they attended, intervention group participants who had teaching hand book were contacted on the end-line survey were included in the final analysis.

\section{RESULT}

\section{Sociodemographic Characteristics}

Out of the 240 T2DM patients planned to include in the study we were able to recruit 220 (116 participants in the intervention group and 104 in the comparison group) and they were included in the baseline analysis. At the end-line, 78 (67\%) of the intervention and 64 (62\%) of the comparison participants were included in the final analysis (Figure 1).

Out of 78 intervention group participants included in the final end-line analysis $6(7.7 \%)$ attended no DSME session, $10(12.8 \%)$ one, 7 (9.0\%) two, 15 (19.2\%) three, 10 (12.8\%) four, 16 (20.5\%) five, and 14 (18.0) six DSME sessions. 
See Table 1 for the sample's baseline sociodemographic characteristics.

\section{Baseline Clinical Characteristics}

At baseline, no significant variations were observed in clinical parameters between the intervention and comparison groups (Table 2).

\section{Glycemic Control}

HbA1c: Chi-square $=1.5795, P=0.208834$. FBS: chisquare $=1.554, P=0.212548$ (baseline $\mathrm{n}$ : intervention $=116$, comparison $=104$; end-line $\mathrm{n}$ : intervention $=78$, comparison $=64$ ).

TABLE 1 | Baseline sociodemographic characteristics of T2DM patients attending JUMC, May 2016.

\begin{tabular}{|c|c|c|c|c|}
\hline \multirow[t]{2}{*}{ Variables } & \multicolumn{2}{|c|}{ Intervention $(n=116)$} & \multicolumn{2}{|c|}{ Comparison $(n=104)$} \\
\hline & Frequency & Percent & Frequency & Percent \\
\hline Age (years) mean \pm SD & $55 \pm 10$ & & $54 \pm 10$ & \\
\hline \multicolumn{5}{|l|}{ GENDER } \\
\hline Male & 81 & 70 & 67 & 64 \\
\hline Female & 35 & 30 & 37 & 36 \\
\hline \multicolumn{5}{|l|}{ EDUCATIONAL STATUS } \\
\hline Illiterate & 20 & 17 & 23 & 22 \\
\hline Grade 1-6 & 33 & 28 & 27 & 26 \\
\hline Grade 7-12 & 39 & 34 & 33 & 32 \\
\hline $\begin{array}{l}\text { College/university } \\
\text { completed }\end{array}$ & 24 & 21 & 21 & 20 \\
\hline \multicolumn{5}{|l|}{ MARITAL STATUS } \\
\hline Married & 98 & 84 & 85 & 82 \\
\hline Widow & 10 & 9 & 10 & 9 \\
\hline Never married & 6 & 5 & 3 & 3 \\
\hline Divorced & 2 & 2 & 6 & 6 \\
\hline \multicolumn{5}{|c|}{ MONTHLY FAMILY INCOME } \\
\hline $\begin{array}{l}\text { Mean monthly family } \\
\text { income in USD* (SD) }\end{array}$ & $93 \pm 123$ & & $87 \pm 77$ & \\
\hline \multicolumn{5}{|c|}{ FINANCIAL SOURCES FOR HEALTH CARE } \\
\hline Out of pocket & 57 & 49 & 60 & 58 \\
\hline Paid by district & 33 & 29 & 36 & 34 \\
\hline Insured & 21 & 18 & 6 & 6 \\
\hline Other & 5 & 4 & 2 & 2 \\
\hline \multicolumn{5}{|l|}{ RESIDENCE } \\
\hline Urban & 81 & 70 & 82 & 79 \\
\hline Rural & 35 & 30 & 22 & 21 \\
\hline \multicolumn{5}{|l|}{ FAMILY STRUCTURE } \\
\hline Nuclear family & 89 & 77 & 76 & 73 \\
\hline Extended family & 21 & 18 & 17 & 16 \\
\hline Living alone & 6 & 5 & 9 & 9 \\
\hline With other individual & - & - & 2 & 2 \\
\hline \multicolumn{5}{|c|}{ HOUSEHOLD FOOD INSECURITY } \\
\hline Secure & 52 & 45 & 53 & 51 \\
\hline Insecure & 64 & 55 & 51 & 49 \\
\hline
\end{tabular}

"1USD at the time 21.18 Ethiopian Birr.
Figure 4 shows an increased proportion of participants with end-line target HbAlc in both the intervention and comparison groups as compared to baseline HbA1c target (Figure 4).

Using an independent sample $t$-test analysis $\mathrm{HbA1c}$ was reduced significantly by $2.88 \%$ (SD $4.28, \mathrm{CI}:-3.85,-1.92$ ) in the intervention group, and by $2.57 \%$ (SD 3.59, CI: -3.47 , -1.67 ) in the comparison group from baseline to end-line., At end-line, the mean HbAlc difference between groups was not significant (Figure 5). Mean end-line FBS was significantly lower in the intervention group, by $27 \pm 10 \mathrm{mg} / \mathrm{dL}$ (CI $-45,-9$; $P=0.003$ ), when adjusted for sociodemographic and clinical factors, including baseline FBS target. However, there was no significant change in FBS within groups (Table 3).

\section{Blood Pressure Control}

When adjusted for sociodemographic and clinical factors (including baseline SBP), mean end-line SBP was significantly lower in the intervention group, by $12 \pm 3 \mathrm{mmHg}(\mathrm{CI}-17,-7 ; P$ $=0.000$ ), than in the comparison group. Similarly, adjusted mean end-line DBP was significantly lower in the intervention group, by $8 \pm 2 \mathrm{mmHg}(\mathrm{CI}-11,-5 ; P=0.000$; Figure 6$)$.

\section{Anthropometric Measurements}

When adjusted for sociodemographic and clinical factors, mean differences between groups with respect to end-line BMI, waist circumference, and waist-to-hip ratio were not significant.

TABLE 2 | Baseline clinical characteristics of T2DM patients attending JUMC, May 2016.

\begin{tabular}{lcc}
\hline Variables & $\begin{array}{c}\text { Intervention } \\
\text { mean (SD) }\end{array}$ & $\begin{array}{c}\text { Comparison } \\
\text { mean (SD) }\end{array}$ \\
\hline Age at diagnosis (in years) & $47(10)$ & $47(10)$ \\
Years lived with diabetes & $10(6)$ & $12(7)$ \\
BMI (kg/m²) & $25(4)$ & $25(4)$ \\
Waist circumference (both & $93(11)$ & $96(11)$ \\
sexes [cm]) & $93(10)$ & $95(10)$ \\
Waist circumference (men & & \\
[cm]) & $94(13)$ & $98(12)$ \\
Waist circumference & & $0.96(0.09)$ \\
(women [cm]) & $0.96(0.06)$ & $0.97(0.08)$ \\
Waist-to-hip ratio (both & & $0.94(0.10)$ \\
sexes) & $0.98(0.06)$ & $125(19)$ \\
Waist-to-hip ratio (men) & $0.94(0.07)$ & $78(11)$ \\
Waist-to-hip ratio (women) & $124(20)$ & $158(65)$ \\
SBP (mmHg) & $79(13)$ & $10(3)$ \\
DBP (mmHg) & $154(61)$ & $7(7)$ \\
FBS (mg/dL) & $11(4)$ & $54(52)$ \\
HbA1c (\%) & $12(10)$ & $43(41)$ \\
TYPE OF MEDICATION-FREQUENCY (\%) & \\
OHAs-frequency (\%) & $73(63)$ & \\
Insulin-frequency (\%) & $31(27)$ & \\
Both OHAs and & & \\
insulin-frequency (\%) & & \\
\end{tabular}

$B M I=$ weight $(\mathrm{kg}) /$ height $(\mathrm{m})^{2}$. 


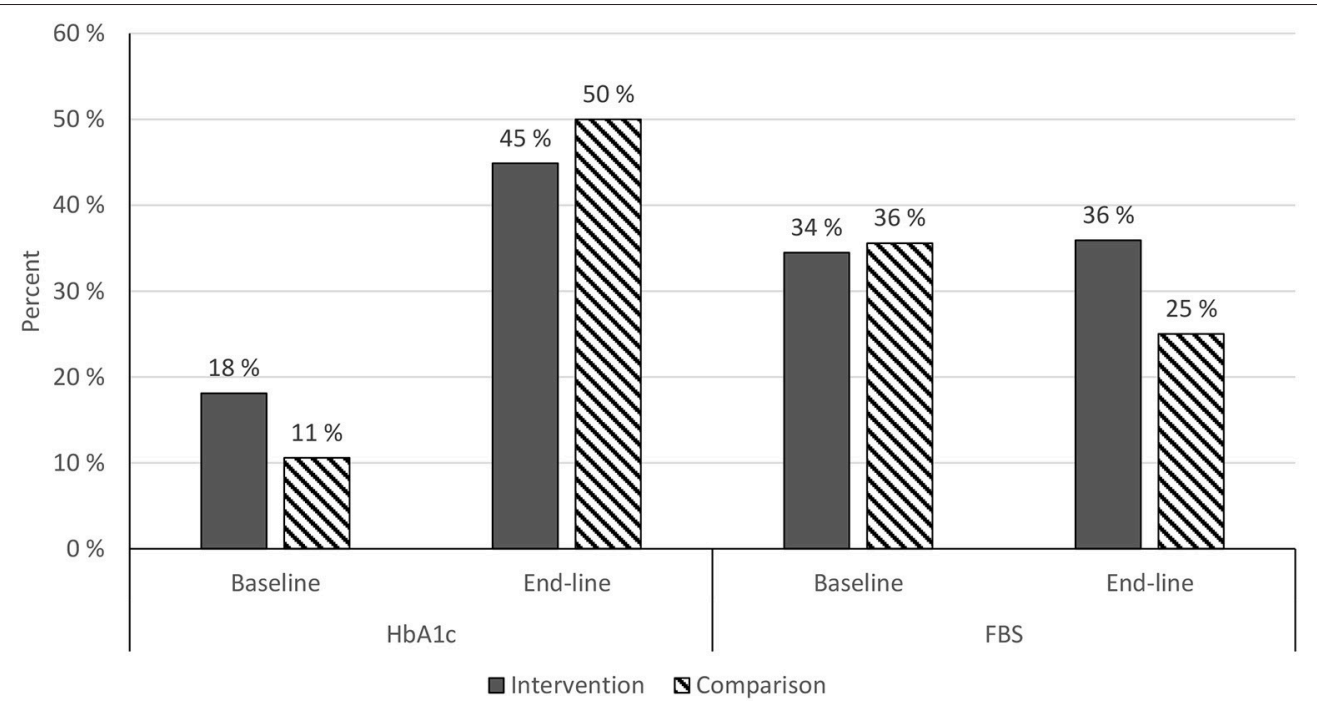

FIGURE 4 | Target baseline and end-line HbA1c and FBS among JUMC diabetic patients, Oct. 2017.

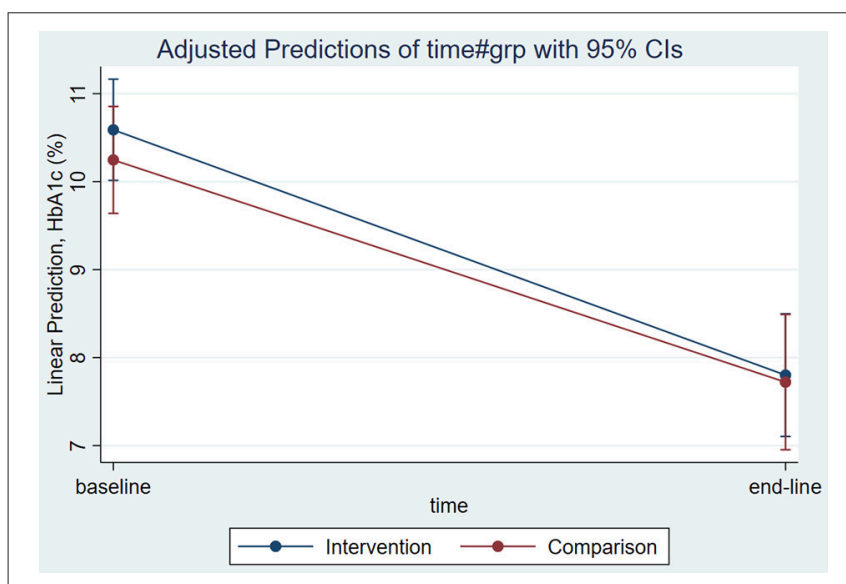

FIGURE 5 | Adjusted mean end-line HbA1c among T2DM patients attending JUMC, Oct. 2017.

\section{DISCUSSION}

In this study, a DSME intervention was investigated as a critical component of diabetes management $(10,28)$. To accommodate low-literate patients and help them engage in self-management, the program was adapted to local context and used illustrative pictures and experience sharing. Our hypothesis is that DSME improves glycemic control over relatively longer time in rural African settings, where the lack of trained health-care providers and medical supplies is a major challenge (28).

Long-term glycemic control is one of the strongest clinicaloutcome indicators of efficient diabetes management and health outcomes (7). The very limited research in Africa has provided inconsistent evidence regarding the clinical significance of $\operatorname{DSME}(7,20,21,29,47-49)$. The current study showed a significant mean $\mathrm{HbA1c}$ drop within both intervention and comparison groups. The drop in both groups is clinically meaningful since a drop of even $<1 \%$ is associated with risk reduction for microvascular and macrovascular complications (50). However, the current study showed that the end-line mean HbAlc difference between groups was not significant. This non-significant difference between groups may be related to information spillover, low attendance rate, LTFU, variation in medication dose/type, and patients' short periods of contact with health providers. Similarly, other studies in Africa have not shown significant difference in HbAlc between intervention and comparison groups $(21,47)$. However, intervention provided over longer period resulted in significant differences in $\mathrm{HbA1c}$ between groups $(20,48,49,51)$. This indicates that DSME provided by well-trained nurses over longer periods of time may be effective for long-term glycemic control. We found significantly lower FBS at end-line in the intervention group, as adjusted for sociodemographic and clinical factors (including baseline values). This is similar to the finding of a study conducted in Egypt (47).

On the other hand, for blood pressure mean end-line SBP and DBP were significantly lower in the intervention group. These finding is consistent with a study conducted in South Africa (21). Even though a drop in blood pressure in diabetic patients is not directly related to glycemic control, it is associated with a clinically significant reduction in the risk of macrovascular and microvascular complications, endpoint diabetes complications, and premature death (52).

The challenges of this study included a low attendance rate and LTFU, because only about half of the participants were present in all six DSME sessions. Transportation challenges, the rainy summer season during which the intervention was conducted, and poor or no network accessibility might be contributing factors. Another possible reasons for the low attendance rate may be transfer of some patients to 
TABLE 3 | End-line fasting blood sugar mean difference between groups, Jimma Oct 2017.

\begin{tabular}{|c|c|c|c|c|c|c|}
\hline Fasting blood sugar & Coef. & Std. Err. & $\mathbf{z}$ & $P>z$ & \multicolumn{2}{|c|}{ [95\% Conf. Interval] } \\
\hline \multicolumn{7}{|l|}{ TIME } \\
\hline Baseline & -14.70667 & 8.190383 & -1.80 & 0.073 & -30.75953 & 1.346182 \\
\hline \multicolumn{7}{|l|}{ GROUP } \\
\hline Intervention & -27.28637 & 9.241271 & -2.95 & 0.003 & -45.39893 & -9.17381 \\
\hline \multicolumn{7}{|l|}{ TIME\# GROUP } \\
\hline Sex & 13.10888 & 7.606254 & 1.72 & 0.085 & -1.799102 & 28.01686 \\
\hline Educational status & 2.227151 & 3.703041 & 0.60 & 0.548 & -5.030677 & 9.484978 \\
\hline Marital status & -8.638841 & 4.975081 & -1.74 & 0.082 & -18.38982 & 1.112137 \\
\hline \multicolumn{7}{|l|}{ RESIDENCY } \\
\hline \multicolumn{7}{|l|}{ Rural $^{*}$} \\
\hline Years lived with DM & -2.48475 & 4.094639 & -0.61 & 0.544 & -10.51009 & 5.540596 \\
\hline Type of medication & -6.751358 & 4.601998 & -1.47 & 0.142 & -15.77111 & 2.268392 \\
\hline \multicolumn{7}{|l|}{ TARGET FBS AT BASELINE } \\
\hline \multicolumn{7}{|l|}{ Not target ${ }^{\star}$} \\
\hline Target & -68.1258 & 6.301119 & -10.81 & 0.000 & -80.47577 & -55.77583 \\
\hline _cons & 230.836 & 29.37252 & 7.86 & 0.000 & 173.2669 & 288.4051 \\
\hline
\end{tabular}

${ }^{*}$ Reference. Bold values: $p<0.05$.

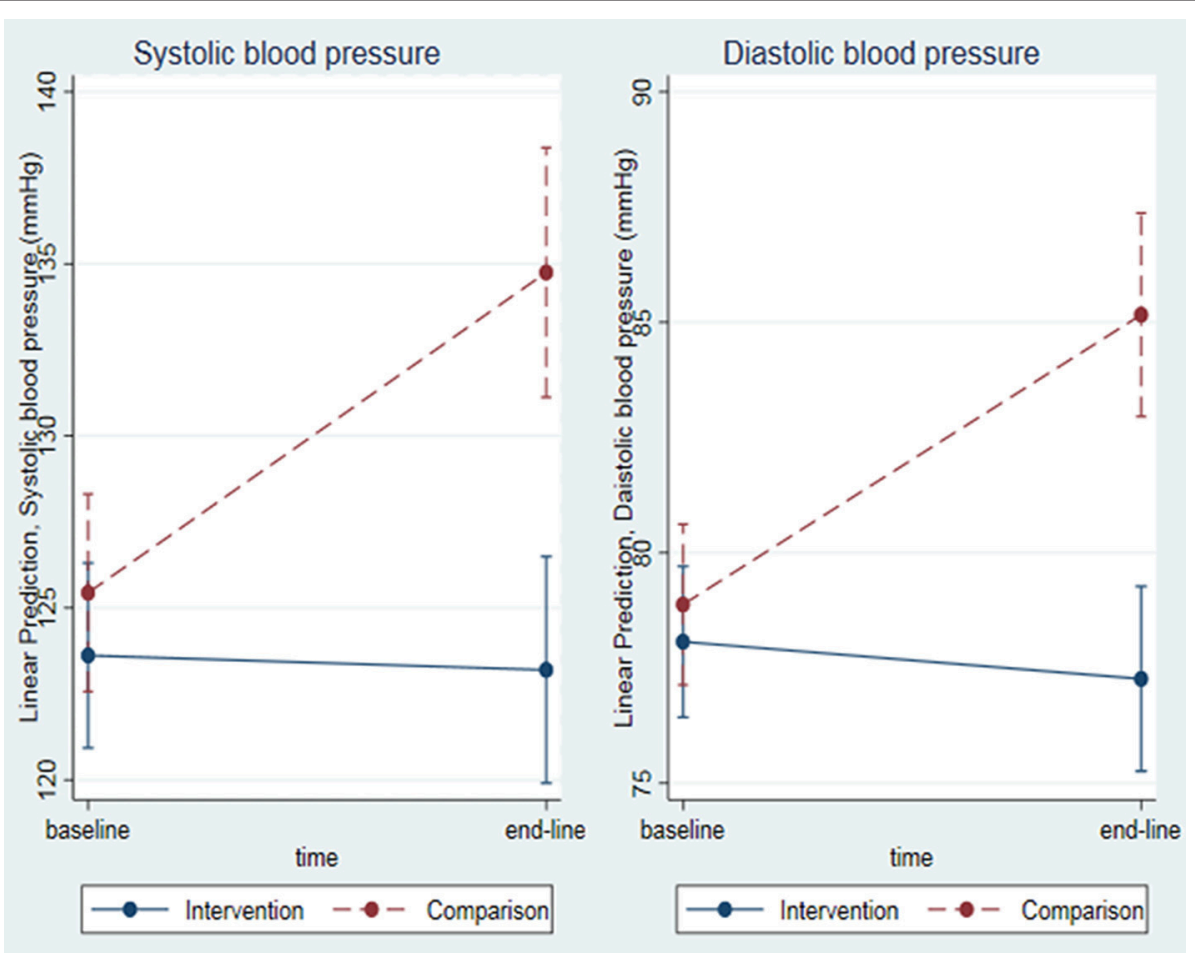

FIGURE 6 | Mean end-line SBP and DBP among T2DM patients attending JUMC, Oct. 2017.

other facilities and frequent and unexpected medication stock out during the intervention period. Logistical issues during transition from the old hospital to the newly built hospital, created a long gap between the baseline and commencement of the intervention, which also may have contributed to LTFU. 
This study has several limitations. First, recruiting both the intervention and the comparison group from the same hospital probably created some information spillover, either verbally or through sharing instructional books and fliers. Second, the gap between the baseline survey and commencement of the intervention could affect measurements. Third, even though we randomized participants based on residence in either Jimma city or districts, there might have been unforeseen selection biases. Fourth, because some of the data collectors were recruited from the same hospital, there might have been social desirability bias.

Despite such limitations, the study contributes important insights for diabetes self-management interventions in Africa. For Sub-Saharan African countries, this study contributes a DSME program supported by instructional handbooks and fliers with illustrative pictures and experience sharing among diabetic patients, are means to accommodate patients with low levels of literacy. The study indicates that it may be effective to use nurses as front-line diabetic-care providers and educators. In addition, the findings show significant improvement in HbAlc in both groups. However, we did not achieve our primary outcome of increasing by $15 \%$ the proportion of diabetes patients in the intervention group with higher glycemic control than patients in the comparison group. The intervention demonstrated significantly lower FBS and SBP and DBP, which are clinically meaningful.

A carefully developed and contextualized DSME program incorporating generous use of pictures and experience sharing is promising in the Ethiopian context. To further strengthen such efforts, additional strategies for delivery, including audio, video messages, teach back and combination of group-based and oneto-one approaches over a longer period that could accommodate low-literate diabetic patients could be investigated $(7,19,28,29)$.

To achieve even more control and reduce the risk of contamination, future studies of DSME should consider designs that incorporate a comparison group from a different hospital or community. In addition, to determine long-term glycemic control, introduction of $\mathrm{HbAlc}$ test laboratory facility to at least specialized, referral, and general hospitals in the country is suggested.

\section{AVAILABILITY OF DATA AND MATERIALS}

The raw data supporting the conclusions of this manuscript will be made available by the authors, without undue reservation, to any qualified researcher upon reasonable request.

\section{REFERENCES}

1. Fekadu S, Yigzaw M, Alemu S, Dessie A, Fieldhouse H, Girma T, et al. Insulinrequiring diabetes in Ethiopia: associations with poverty, early undernutrition and anthropometric disproportion. Eur J Clin Nutr. (2010) 64:1192-8. doi: 10.1038/ejen.2010.143

2. Idemyor V. Diabetes in sub-Saharan Africa: health care perspectives, challenges, and the economic burden of disease. J Nat Med Assoc. (2010) 102:650-3. doi: 10.1016/S0027-9684(15)30643-X

\section{ETHICS STATEMENT}

All procedures performed in studies involving human participants were in accordance with the ethical standards of the institutional and/or national research committee and with the 1964 Helsinki declaration and its later amendments or comparable ethical standards. Before the commencement of the study, ethical approval was secured from the Norwegian Regional Committee for Medical and Health Research Ethics (REK) and the Jimma University Ethical Review Board. Written informed consent was obtained from all individual participants included in the study.

\section{AUTHOR CONTRIBUTIONS}

All authors made a substantial contribution, from proposal development and study design to the writing of the manuscript. Specifically, FH conceived the idea and developed the study proposal, did the fieldwork, analyzed data, interpreted the findings, and led the manuscript writing. $\mathrm{PH}$ was involved in proposal development, planning the fieldwork, data analysis and interpretation, manuscript editing and manuscript review. AM was involved in proposal development, planning the fieldwork, data interpretation, manuscript editing and manuscript review. All authors approved this manuscript for publication.

\section{FUNDING}

This research project was funded by the Norwegian Programme for Capacity Development in Higher Education and Research for Development (NORHED) under the NORHED-Programme, Agreement no. ETH-13/0024.

\section{ACKNOWLEDGMENTS}

We thank the study participants for their commitment to providing information and blood samples, and to participating in the DSME intervention in the study until its conclusion. We also extend our gratitude to the DSME providers and data collectors for their immense contribution. Lastly, we acknowledge the funding and support from the SACCADE (Strategic and Collaborative Capacity Development in Ethiopia and Africa) project funded under the NORHED program for capacity building making this study possible. 
6. IDF. Diabetes Atlas: Regional Fact Sheets 2017 Feb 25 (2018).

7. Chrvala CA, Sherr D, Lipman RD. Diabetes self-management education for adults with type 2 diabetes mellitus: a systematic review of the effect on glycemic control. Patient Edu Counsel. (2016) 99:926-43. doi: 10.1016/j.pec.2015.11.003

8. Embrey N. A concept analysis of self-management in long-term conditions. Br J Neurosci Nurs. (2006) 2:507-13. doi: 10.12968/bjnn.2006.2.10.22535

9. Lorig KR, Holman HR. Self-management education: history, definition, outcomes, and mechanisms. Ann Behav Med. (2003) 26:1-7. doi: 10.1207/S15324796ABM2601_01

10. Haas L, Maryniuk M, Beck J, Cox CE, Duker P, Edwards L, et al. National standards for diabetes self-management education and support. Diab Care (2013) 36(Suppl. 1):S100-S8. doi: 10.2337/dc13-S100

11. Loveman E, Frampton GK, Clegg AJ. The clinical effectiveness of diabetes education models for Type 2 diabetes: a systematic review. Health Technol Assess. (2008) 12:1-116. doi: 10.3310/hta12090

12. IDF. International standards for education of diabetes health professionals. Int Diab Federat. (2015). Available online at: https://www.idf.org/e-library/ education/63-international-standards-for-education- of-diabetes-healthprofessionals.html (Accessed June 26, 2015).

13. Akabane M, Konishi H, Nishio Y, Yamaji A. Long-Term glycemic control after a one week hospital education program for inpatients with type 2 diabetes. $J$ Pharm Technol. (2007) 23:263-9. doi: 10.1177/875512250702300502

14. Baradaran HR, Knill-Jones RP, Wallia S, Rodgers A. A controlled trial of the effectiveness of a diabetes education programme in a multi-ethnic community in Glasgow [ISRCTN28317455]. BMC Public Health (2006) 6:134. doi: 10.1186/1471-2458-6-134

15. Clark M. Diabetes self-management education: a review of published studies. Prim Care Diabet. (2008) 2:113-20. doi: 10.1016/j.pcd.2008.04.004

16. D'Eramo-Melkus GA, Wylie-Rosett J, Hagan JA. Metabolic impact of education in NIDDM. Diabetes Care (1992) 15:864-9. doi: $10.2337 /$ diacare.15.7.864

17. Ellis SE, Speroff T, Dittus RS, Brown A, Pichert JW, Elasy TA. Diabetes patient education: a meta-analysis and meta-regression. Patient Edu Counsel. (2004) 52:97-105. doi: 10.1016/S0738-3991(03)00016-8

18. Özer E, Sengül AM, Gedik S, Salman S, Salman F, Sargin M, et al. Diabetes education: a chance to improve well-being of Turkish people with type 2 diabetes. Pat Educ Counsel. (2003) 51:39-44. doi: 10.1016/S0738-3991(02)00246-X

19. Deakin T, McShane CE, Cade JE, Williams R. Group based training for selfmanagement strategies in people with type 2 diabetes mellitus. Cochrane Database Syst Rev. (2005) 2:1-90. doi: 10.1002/14651858.CD003417.pub2

20. Essien O, Otu A, Umoh V, Enang O, Hicks JP, Walley J. Intensive patient education improves glycaemic control in diabetes compared to conventional education: a randomised controlled trial in a nigerian tertiary care hospital. PLoS ONE (2017) 12:e0168835. doi: 10.1371/journal.pone.0168835

21. Mash R, Rhode H, Zwarenstein M, Rollnick S, Lombard C, Steyn K, et al. Effectiveness of a group diabetes education programme in under served communities in South Africa: a pragmatic cluster randomized controlled trial. Diabet Med. (2014) 31:987-93. doi: 10.1111/dme.12475

22. Bai YL, Chiou CP, Chang YY. Self-care behaviour and related factors in older people with Type 2 diabetes. J Clin Nurs. (2009) 18:3308-15. doi: 10.1111/j.1365-2702.2009.02992.x

23. Bawadi HA, Ammari F, Abu-Jamous D, Khader YS, Bataineh Sa, Tayyem RF. Food insecurity is related to glycemic control deterioration in patients with type 2 diabetes. Clin Nutr. (2012) 31:250-4. doi: 10.1016/j.clnu.2011.09.014

24. Gucciardi E, DeMelo M, Offenheim A, Grace SL, Stewart DE. Patient factors associated with attrition from a self management education programme. J Eval Clin Pract. (2007) 13:913-9. doi: 10.1111/j.1365-2753.2006.00773.x

25. Heerman W, Wallston K, Osborn C, Bian A, Schlundt D, Barto S, et al. Food insecurity is associated with diabetes self care behaviours and glycaemic control. Diabet Med. (2015) 33:844-50. doi: 10.1111/dme.12896

26. Mayer VL, McDonough K, Seligman H, Mitra N, Long JA. Food insecurity, coping strategies and glucose control in low-income patients with diabetes. Public Health Nutr. (2016) 19:1103-11. doi: 10.1017/S1368980015002323

27. Mogre V, Abanga ZO, Tzelepis F, Johnson NA, Paul C. Adherence to and factors associated with self-care behaviours in type 2 diabetes patients in Ghana. BMC Endocr Dis. (2017) 17:20. doi: 10.1186/s12902-017-0169-3
28. Norris SL, Lau J, Smith SJ, Schmid CH, Engelgau MM. Selfmanagement education for adults with type 2 diabetes: a meta-analysis of the effect on glycemic control. Diabetes Care. (2002) 25:1159-71. doi: $10.2337 /$ diacare.25.7.1159

29. Dube L, Van den Broucke S, Housiaux M, Dhoore W, Rendall-Mkosi K. Type 2 diabetes self-management education programs in high and low mortality developing countries: a systematic review. Diabetes Edu. (2015) 41:69-85. doi: 10.1177/0145721714558305

30. Al Sayah F, Williams B, Pederson JL, Majumdar SR, Johnson JA. Health literacy and nurses' communication with type 2 diabetes patients in primary care settings. Nurs Res. (2014) 63:408-17. doi: 10.1097/NNR.0000000000000055

31. Ezenwaka C, Eckel J. Prevention of diabetes complications in developing countries: time to intensify self-management education. Arch Physiol Biochem. (2011) 117:251-3. doi: 10.3109/13813455.2011.602692

32. Angamo MT, Melese BH, Ayen WY. Determinants of glycemic control among insulin treated diabetic patients in Southwest Ethiopia: hospital based cross sectional study. PLOS ONE (2013) 8:e61759. doi: 10.1371/journal.pone.0061759

33. ADA. Living With Diabetes. ADA. Available online at: http://www.diabetes. org/living-with-diabetes/?loc=lwd-slabnav (Accessed May 23, 2015).

34. FMHACAE. (Eds). List of medicines for Ethiopia. In: Food MaHCAaCAoE. 6th ed. Addis Ababa: Ethiopian Federal Ministry of Health (2010).

35. Health HSoP. Healthy Eating Plate \& Healthy Eating Pyramid. Available online at: http://www.hsph.harvard.edu/nutritionsource/healthy-eatingplate/ (Accessed March 12, 2015).

36. IDF. International Curriculum for Diabetes Health Professionals Education. Available online at: https://www.idf.org/e-library/education/64-theinternational-curriculum-for-diabetes-health-professional-education, en.html (Accessed June 25, 2015).

37. IDF. Diabetes Education Training Manual for Sub-Saharan Africa. Jamana Printers Ltd. 2006. Available online at: http://www.worlddiabetesfoundation. org/sites/default/files/DETM\%20Eng.pdf (Accessed June 26, 2015).

38. Kate Lorig HH, David Sobel, Diana Laurent, Virginia Gonzale, Marian Minor. Living Healthy Life with Chronic Conditions. Boulder, NV: Bull Publishing Company (2012).

39. UK D. Care Connect Campaign: What to do when you have type 2 diabetes: An easy read guide. Available online at: https://www.changepeople. org/Change/media/Change-Media-Library/Free\%20Resources/Type-2Diabetes-CHANGE-web.pdf (Accessed March 12, 2015).

40. Mulcahy K, Maryniuk M, Peeples M, Peyrot M, Tomky D, Weaver T, et al. Diabetes self-management education core outcomes measures. Diabet Educ. (2003) 29:768-803. doi: 10.1177/0145721703029 00509

41. Gebreyesus SH, Lunde T, Mariam DH, Woldehanna T, Lindtiørn B. Is the adapted household food insecurity access scale (HFIAS) developed internationally to measure food insecurity valid in urban and rural households of Ethiopia? BMC Nutr. (2015) 1:2. doi: 10.1186/20550928-1-2

42. Workman CL, Ureksoy H. Water insecurity in a syndemic context: understanding the psycho-emotional stress of water insecurity in lesotho, Africa. Soc Sci Med. (2017) 179:52-60. doi: 10.1016/j.socscimed.2017. 02.026

43. ADA. Executive Summary: Standards of Medical Care in Diabetes. Diabetes Care (2011) 34:S4-S10. doi: 10.2337/dc11-S004

44. De Boer IH, Bangalore S, Benetos A, Davis AM, Michos ED, Muntner P, et al. Diabetes and hypertension: a position statement by the American diabetes association. Diab Care (2017) 40:1273-84. doi: 10.2337/dci17-0026

45. WHO. Waist Circumference and Waist-Hip Ratio: Report of a WHO Expert Consultation. Geneva: WHO (2008).

46. Coates J, Swindale A, Bilinsky P. Household Food Insecurity Access Scale (HFIAS) for Measurement of Food Access: Indicator Guide. Washington, DC: Food and Nutrition Technical Assistance Project, Academy for Educational Development (2007).

47. Abaza H, Marschollek M. SMS education for the promotion of diabetes self-management in low \& middle income countries: a pilot randomized controlled trial in Egypt. BMC Public Health (2017) 17:962. doi: 10.1186/s12889-017-4973-5 
48. Gill G, Price C, Shandu D, Dedicoat M, Wilkinson D. An effective system of nurse-led diabetes care in rural Africa. Diabet Med. (2008) 25:606-11. doi: 10.1111/j.1464-5491.2008.02421.x

49. Debussche X, Besancon S, Balcou-Debussche M, Ferdynus C, Delisle $\mathrm{H}$, Huiart L, et al. Structured peer-led diabetes self-management and support in a low-income country: the ST2EP randomised controlled trial in Mali. PLoS ONE (2018) 13:e0191262. doi: 10.1371/journal.pone. 0191262

50. Srimanunthiphol J, Beddow R, Arakaki R. A review of the United Kingdom prospective diabetes study (UKPDS) and a discussion of the implications for patient care. Hawaii Med J. (2000) 59:295-8.

51. Assah FK, Atanga EN, Enoru S, Sobngwi E, Mbanya JC. Communitybased peer support significantly improves metabolic control in people with Type 2 diabetes in Yaounde, Cameroon. Diab Med. (2015) 32:886-9. doi: $10.1111 / \mathrm{dme} .12720$
52. Group UPDS. Tight blood pressure control and risk of macrovascular and microvascular complications in type 2 diabetes: UKPDS 38. BMJ (1998) 317:703. doi: 10.1136/bmj.317.7160.703

Conflict of Interest Statement: The authors declare that the research was conducted in the absence of any commercial or financial relationships that could be construed as a potential conflict of interest.

Copyright (c) 2018 Hailu, Hjortdahl and Moen. This is an open-access article distributed under the terms of the Creative Commons Attribution License (CC BY). The use, distribution or reproduction in other forums is permitted, provided the original author(s) and the copyright owner(s) are credited and that the original publication in this journal is cited, in accordance with accepted academic practice. No use, distribution or reproduction is permitted which does not comply with these terms. 